\title{
RI79: UM NOVO DERIVADO TIAZOLIDINICO PARA O TRATAMENTO DO MELANOMA
}

\author{
$\underline{\text { M.C.P.DUARTE SAMPAIO }}^{1}$ M.G.R. PITTA ${ }^{1}$, R.B DE OLIVEIRA $^{2}$, M.J.B.M. REGO ${ }^{1}$ \\ 1 Laboratório de Imunomodulação e Novas Abordagens Terapêuticas (LINAT), da \\ Universidade Federal de Pernambuco (UFPE), Recife, Brasil. \\ ${ }^{2}$ Universidade Federal de Minas Gerais (UFMG)
}

e-mail: clarapds@gmail.com

Resumo - O melanoma é o tipo mais letal de câncer de pele, que vem mudando seu perfil de incidência no mundo nos últimos anos. Sua alta taxa de letalidade é devesse principalmente ao seu grande potencial metastático e por desenvolver resistência a tratamento. Dessa forma, a busca de novos tratamentos mais eficaz se faz necessário. Com o objetivo de procurar novas alternativas para o tratamento do melanoma foi realizado o presente estudo. Para atender esse objetivo foi realizada a síntese de nove derivados tiazolidinico e os mesmos foram avaliada a sua toxicidade nas concentrações de 5, 10 e $100 \mathrm{Mm}$ frente três diferentes linhagens de melanoma UACC62, A375 e SKMEL-28. Um dos derivados RI79 obteve o IC50 de 7,249658 Mm na linhagem de SKMEL-28.

Palavras-chave: SK-MEL-28, Citotoxicidade, antineoplasico

\begin{abstract}
- melanoma is the most lethal type of skin cancer, which has been changing its incidence profile in the world in recent years. its high lethality rate is due mainly to its great metastatic potential and to develop resistance to treatment. in this way, the search for new treatments more effectively becomes necessary. in order to find new alternatives for the treatment of melanoma, the present study was carried out. in order to meet this objective, nine thiazolidinic derivatives were synthesized and their toxicity was evaluated at concentrations of 5, 10 and $100 \mathrm{~mm}$ against three different melanoma strains uacc 62 , a375 and sk-mel-28. one of the derivatives ri79 obtained the ic 50 of $7.249658 \mathrm{~mm}$ in the strain of sk-mel-28.
\end{abstract}

Keywords: SK-MEL-28, Cytotoxicity, antineoplastic

\section{INTRODUÇÃO}

O melanoma é um tipo de câncer de pele que tem aumentando sua incidência no mundo nos últimos 30 anos, se tornando um problema de saúde pública por apresentar alta letalidade. Devido principalmente do seu grande potencial metastático tendo como principais sítios de metástase o pulmão e o cérebro. A metástase cerebral representa um prognostico reservado causando problemas neurológicos diminuindo a qualidade de vida dos pacientes, além de representar alta taxa de mortalidade (INCA,2016). 
Em casos de diagnostico inicias do melanoma as chances de cura chegam a 92\% e taxa de sobrevivência de dez anos de 89\% (SIEGEL; MILLER; JEMAL, 2016). Contudo, estágios avançados com metástase as taxas de sobrevida de cinco anos caem de $98 \%$ para $17 \%$, esses pacientes apresentam sobrevida média global de apenas 6 a 9 messes (LIU et al., 2017). O melanoma tem preferência por metástases distantes sendo os seus principais sítios metastáticos o pulmão e o cérebro (ISOLA; EDDY; CHEN, 2016), levando a morte em cerca de 20 a 54\% dos casos (STELZER, 2013).

Uma das dificuldades no tratamento do melanoma é que normalmente os mesmos desenvolvem resistência (ISOLA; EDDY; CHEN, 2016). Por esse motivo se faz necessário estudos que busquem novos medicamentos mais eficazes para o tratamento dessa neoplasia. As tiazolidinas (TZD) são moléculas que apresentam grande potencial antineoplásico por agiram nos receptores ativados por peroxissoma gama (PPAR $\gamma$ ), (WUERTZet al., 2017). A PPAR $\gamma$ está presente em diversas linhagens tumorais humanas além de estar envolvido no controle da proliferação e apoptose celular. Dessa forma, o presente estudo analisou derivados tiazolidinicos frente linhagens de melanoma.

\section{MATERIAIS E MÉTODOS}

\subsection{Obtenção dos Compostos}

Os compostos tiazolidínicos estudados foram gentilmente concedidos pela Profa. Dra. Renata Barbosa de Oliveira, da Universidade Federal de Minas Gerais (UFMG)

\subsection{Cultura}

Foram utilizadas três linhagens de melanoma a SK-MEL28 (Banco de Células do Rio de Janeiro - BCRJ), a A375 (BCRJ) e a UACC62, essas última gentilmente cedida pelo Prof. Dr.Roger Chammas, do Instituto do Câncer do Estado de São Paulo (ICESP) Faculdade de Medicina da Universidade de São Paulo (FMUSP). A SK-MEL-28 é cultivada no meio DMEM (Dulbecco's Modified Eagle Medium - Dulbecco's) suplementado com SFB a 10\%. Já a UACC62 e A375 são cultivadas no meio DMEM High Glicose (Dulbecco's) também com a suplementação do SFB a 10\%.

\subsection{Teste de Citotoxicidade}

Foram realizados experimentos independentes em placas de 96 poços com concentração final de $1 \times 10^{6}$ células/poço. As doses de 5, 10 e $100 \mu \mathrm{g} / \mathrm{mL}$ dos derivados foram adicionadas em triplicata. Após 72 horas de incubação, O MTT foi adicionado no volume de $20 \mu 1 /$ poço. Após o período de 24 horas de incubação, foram feitas as leituras em espectrofotômetro de placa (a $550 \mathrm{~nm}$ ).

\section{RESULTADOS E DISCUSSÃO}

Os nove derivados foram testados frente linhagens as linhagens de melanoma UACC62, A375 e SK-MEL28.O melanoma é uma neoplasia que tem como característica o envolvimento de diversas mutações entre essa a mutação do gene BRAF comum em melanoma metastático agressivo (MCCUBREY et al., 2012). Essa mutação encontrasse presente nas três linhagens utilizadas no estudo. Acreditasse que essas mutações são 
importantes no processo de resistência ao tratamento comum no melanoma (DAVIES, H.,2002). Na UACC62, A375 nenhum dos compostos conseguiu ser toxico. Contudo, na SK-MEL28 uma linhagem mais agressiva que comumente não responde bem a tratamentos o composto RI79 conseguiu ser toxico como demostra a figura 1 diminuindo a viabilidade celular da SK-MEL-28 com o aumento da concentração do RI79 apresentando o IC 50 de 7,2 $\mu \mathrm{M}$. Ainda não é possível determinar o motivo do RI79 apresentar atividade toxica para a linhagem SK-MEL-28 deferentemente dos outros compostos, entretanto o RI79 e a molécula com maior peso molecular, acreditasse que esse pode ser um dos motivos.

Figura 1 : Gráfico dose resposta do RI79 frente a linhagem SK-MEL-28

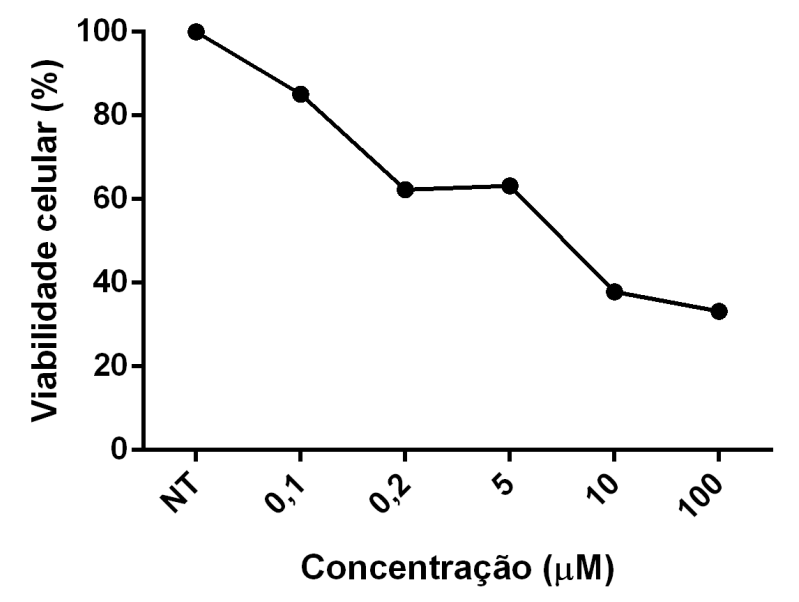

\section{CONCLUSÕES}

Os derivados tiazolidinicos não foram toxico nas linhagens UACC62 e A375.O RI79 apresentou resultados promissores frente a linhagem SK-MEL-28, contudo novas analises devem ser realizadas para melhor compreender os mecanismos utilizado pelo composto para conseguir se eficaz nessa linhagem diferentemente do que ocorre nas outras linhagens de melanoma.

\section{REFERÊNCIAS BIBLIOGRÁFICAS}

DAVIES, H. Mutations of the BRAF gene in human cancer. Nature, v. 417, n. 6892, p. 949-954, 2002.

ISOLA, A. L.; EDDY, K.; CHEN, S. Biology, Therapy and Implications of Tumor Exosomes in the Progression of Melanoma. p. 1-18, 2016.

LIU, Q. DAS M. , YUN L., HUANG L. Targeted Drug Delivery to Melanoma. Advanced Drug Delivery Reviews, 2017.

MCCUBREY, J. A., CHAPPELL W.H., ABRAMS S.L., FRANKLIN R.A., MONTALTO G, Ras/Raf/MEK/ERK and PI3K/PTEN/Akt/mTOR Cascade Inhibitors: How Mutations Can Result in Therapy Resistance and How to Overcome Resistance. Oncotarget, v. 33, n. 10, p. 1068-1111, 2012z 
SIEGEL, R. L.; MILLER, K. D.; JEMAL, A. Cancer statistics. CA Cancer J Clin, v. 66, n. 1, p. 7-30, 2016.

WUERTZ, B. R., DARRAH L.,WUDEL J. ,ONDREY FG . Thiazolidinediones abrogate cervical cancer growth. Experimental Cell Research, v. 353, n. 2, p. 63-71, 2017.

\section{AGRADECIMENTOS}

Ao INCT_if. 